\title{
ISOFLAVONAS DE SOJA - UMA BREVE REVISÃO
}

\section{SOYBEAN ISOFLAVONES - A SHORT REVIEW}

\author{
ROSELI APARECIDA FERRARI ${ }^{1}$ \\ IVO MOTTIN DEMIATE ${ }^{1}$ \\ ${ }^{1}$ Professores do Departamento de Zootecnia \\ e Tecnologia de Alimentos UEPG
}

\begin{abstract}
RESUMO
Evidências sugerem que o consumo de soja está associado com benefícios à saúde, fato que criou considerável expectativa na comunidade dietética e nutricional. Contudo, grande parte da pesquisa sobre este tema permanece em andamento como uma questão polêmica na literatura. Por essa razão, a intenção deste artigo é fazer um breve resumo de pesquisas sobre os efeitos benéficos de alimentos à base de soja, enfocando, como principal interesse, seu teor de isoflavonas.
\end{abstract}

Palavras-chave: soja, isoflavonas, produtos de soja

\section{Introdução}

O crescente interesse por alimentos denominados genericamente de nutracêuticos coloca a soja em uma posição de destaque novamente. Em 
princípio a sua importância nutricional era relacionada exclusivamente ao elevado teor protéico, tendo sido chamada por alguns de "carne vegetal". Atualmente outros componentes da soja têm despertado considerável interesse na comunidade científica, especialmente as isoflavonas.

O consumo de alimentos a base de leguminosas e especificamente de soja em países orientais tem sido associado às boas condições de saúde das populações. Comparações entre dietas e algumas doenças têm demonstrado a importância do consumo de alguns alimentos, entre os quais aqueles obtidos a partir de soja. Essas constatações têm sido associadas à presença de isoflavonas nesses alimentos.

\section{Revisão de literatura}

\section{1. Isoflavonas}

Isoflavonas representam uma classe de compostos químicos conhecidos como fitoestrógenos encontrados em grãos de soja e produtos derivados, ligados ou não com moléculas de açúcar. Dois tipos principais de isoflavonas de soja são a genisteina e daidzeina, ou suas respectivas formas com glicosídeos, a genistina e daidzina. Estes compostos bioativos e não nutricionais apresentam estrutura química similar ao estradiol, o principal hormônio feminino e assim se encaixam nos receptores de estrógeno. Desta forma, as isoflavonas apresentam a habilidade de imitar os estrógenos, apresentando propriedades fisiológicas suficientes para atrair a atenção de muitos pesquisadores para os seus efeitos e benefícios à saúde e na reposição hormonal (EUGENBIO, 2001).

\section{2. Efeitos no organismo}

Os legumes têm importante papel nas dietas de populações de algumas regiões do mundo. Em contraste, nos países ocidentais esses vegetais tendem a ter um papel minoritário na dieta, mesmo sabendo-se que apresentam elevado teor protéico, fibra dietética e uma variedade de micronutrientes e compostos fitoquímicos. A soja é única entre as leguminosas porque é uma fonte concentrada de isoflavonas. As isoflavonas 
apresentam propriedades estrogênicas fracas. Alimentos a base de soja e contendo isoflavonas têm recebido considerável atenção pelo seu papel potencial na prevenção e tratamento de câncer e de osteoporose. Os baixos índices de mortalidade causada por câncer de mama em países asiáticos e os efeitos anti-estrogênicos das isoflavonas alimentam a especulação de que a ingestão de alimentos de soja reduz os riscos do desenvolvimento da doença. Os dados epidemiológicos são limitados e suportam fragilmente essa hipótese, particularmente para câncer de mama pós-menopausa. Há dados mais consistentes de redução do risco de câncer de próstata. Os fracos efeitos estrogênicos das isoflavonas e a similaridade da estrutura química entre as isoflavonas da soja e a isoflavona sintética ipriflavona, que se mostrou ativa no aumento da densidade mineral dos ossos em mulheres após a menopausa, sugere que a soja ou as isoflavonas podem reduzir o risco da ocorrência de osteoporose (MESSINA, 1999).

Em um trabalho de revisão Anderson et al. (1999) abordaram os efeitos de fitoestrógenos sobre tecidos animais, destacando a capacidade desses compostos em melhorar a saúde humana principalmente por protegerem o organismo contra certas doenças crônicas, entre as quais os problemas cardiovasculares, alguns tipos de câncer e a osteoporose. Os níveis de fitoestrógenos no sangue podem ser mantidos elevados pelo consumo diário de alimentos obtidos de soja.

Endo (1998) fez uma revisão a respeito da utilização de subprodutos de várias fábricas de alimentos, incluindo aquelas processadoras de soja. Discutiu a obtenção, a partir de subprodutos, de substâncias de elevado valor econômico, entre as quais as isoflavonas da soja.

Mazur e Adlercreutz (1998) afirmam que plantas comestíveis contêm alguns compostos naturais que mimetizam os efeitos biológicos de estrogênios devido a habilidade em se ligar e ativar os receptores nucleares de estrogênio. Esses compostos, parecidos com hormônio, fitoestrógenos difenólicos de origem dietética, incluem os isoflavonóides. O interesse por esses compostos é grande e deriva de resultados de estudos epidemiológicos em dietas e doenças ocidentais, incluindo alguns tipos de câncer dependentes de hormônios e doenças cardíacas. A incidência desses tipos de enfermidades é menos comum em populações dos países asiáticos que nos habitantes da Europa e América do Norte. Os autores empregaram a diluição de isótopos e a cromatografia a gás - espectrometria de massas (GC-MS) para quantificar os precursores em alimentos desses compostos, detectados no plasma de habitantes de regiões com baixa incidência de câncer. Entre os 
compostos, foram encontradas a daidzeina e a genisteina, que apresentam propriedades de estrogênios e são compostos que têm ação antiproliferativa de células cancerígenas em cultivo. Os autores reportam resultados da quantificação de estrogênios em várias plantas, incluindo a soja.

Produtos obtidos de plantas cultivadas podem se tornar fontes baratas de fito-nutrientes, como suplementos alimentares anti-mutagênicos. Plewa et al. (1999) demonstraram que o extrato alcoólico de um subproduto do processamento de soja foi capaz de reprimir danos induzidos no DNA e mutações em células de mamíferos. Os autores afirmam que esse extrato continha os flavonóides daidzeina e genisteina, que reprimiram danos no DNA induzidos por 2-acetoxiacetilaminofluorene (2-AAAF), medidos por eletroforese em gel. Concluíram que produtos e subprodutos de soja podem ser importantes fontes de aditivos alimentícios quimioprotetivos.

Conforme Hsu et al. (1999), o fitoestrogênio dietético daidzeina reduziu a proliferação de células de carcinoma de mama humana cultivadas em laboratório. O crescimento dessas células foi inibido por doses acima de $25 \mathrm{mg} / \mathrm{mL}$.

Eldridge e Kwolek (1983) consideraram os efeitos ambientais e de variedades nas isoflavonas e glicosídeos de isoflavona de soja. A extração de óleo não remove as isoflavonas ou seus glicosídeos, pois estes não são solúveis em hexano. O conteúdo total de isoflavonas na soja variou de 116 a 309 mg/g entre variedades e de 46 a 195 mg/g na mesma variedade cultivada em diferentes localidades. A maior parte das isoflavonas está concentrada no hipocótilo e o seu conteúdo na casca é bem baixo.

Barnes et al. (1994) identificaram conjugados glicosídicos de isoflavona de vários produtos de soja por cromatografia líquida de alta eficiência - espectrometria de massa. Extraíram isoflavonas dos produtos de soja com solução aquosa de metanol (80\%) à temperatura ambiente, evitando a extração a quente que pode causar mudanças na composição das isoflavonas. Grãos e farelos desengordurados de soja continham em maior concentração conjugados 6-O-malonilglicosídeos, com menores quantidades de b-glicosídeos e apenas quantidades traço de conjugados 6-Oacetilglicosídeos.

A evidência de que as isoflavonas naturais protegem contra algumas doenças crônicas é constatada por observação epidemiológica assim como experimentalmente. Em humanos, estudos epidemiológicos mostram uma grande incidência de certos tipos de câncer (mama, próstata e cólon) e de doenças cardíacas em populações ocidentais que consomem quantidades 
de isoflavonas de soja muito limitadas (genisteina e daidzeina). As isoflavonas podem também prevenir a perda de massa óssea e osteoporose em mulheres na menopausa. A isoflavona sintética ipriflavona reduziu a perda óssea em animais de laboratório, o que indica seu emprego para prevenção de osteoporose em mulheres na menopausa (BRANDI, 1997).

Em busca de uma fonte abundante e favorável economicamente das isoflavonas genisteina e daidzeina, Hessler et al. (1997) descobriram que o microrganismo produtor de eritromicina (Saccharopolyspora erythrea) também produzia esses novos e promissores agentes preventivos de câncer. A fermentação para produção de eritromicina é feita em grande escala, em substrato a base de soja em todo o mundo. A genisteina foi co-extraída com a eritromicina do meio de fermentação e separada do antibiótico durante a segunda etapa de purificação.

Pesquisadores da Protein Technologies International (1999) extraíram isoflavonas de produtos de soja pela suspensão do material seco triturado em solução aquosa de metanol. A mistura foi agitada e filtrada para o isolamento das isoflavonas, que foram separadas por cromatografia líquida de alta eficiência.

As isoflavonas (genistina, daidzina e glicitina) são encontradas apenas na soja, sendo antioxidantes naturais. Desativam radicais livres no organismo defendendo-o contra a ação maléfica desses compostos (CAI e WEI, 1996). São classificadas como fitoestrogênios, ou seja, são estrogênios naturais presentes em plantas. Os estrogênios vegetais competem com aqueles produzidos no corpo ou introduzidos do ambiente e evitam que os estrógenos se liguem com as células receptoras (NOTEBOOM e GORSKI, 1963).

O benefício é que os estrógenos de soja reduzem a absorção e o uso de estrógenos potencialmente perigosos. Os fitoestrógenos fracos da soja influenciam nos hormônios sexuais, na síntese de proteínas e na diferenciação e proliferação celular (MARTIN et al., 1978; ADLERCREUTZ et al., 1992).

O consumo de proteína de soja tem sido associado com a redução da hipercolesterolemia e do risco de ataque cardíaco. Contudo, Lucas et al. 2001, avaliaram o efeito de componentes de isolados protéicos de soja na variação do teor de lipídios de hamsters. Nenhum efeito significativo foi observado no teor de lipídios totais ou na quantidade de colesterol do fígado. Afirmaram que os resultados concordam com observações anteriores que isoflavonas e outros componentes não protéicos precisam ser investi- 
gados em outros estudos.

\title{
3. Considerações finais
}

As isoflavonas presentes na soja e que não são removidas pela extração do óleo têm sido citadas em muitos trabalhos científicos como potencialmente benéficas à saúde humana. Geralmente esses benefícios têm sido constatados quando se comparam populações orientais com ocidentais, considerando-se a ingestão de alimentos obtidos a partir de soja pelas primeiras. Alguns experimentos laboratoriais também são citados como provas dos efeitos benéficos das isoflavonas especialmente em relação a alguns tipos de câncer e ao problema de osteoporose.

É necessário, entretanto, observar essas informações com cautela uma vez que as isoflavonas são compostos com atividade estrogênica e há muita polêmica nessa área. Alguns trabalhos mais recentes começam a levantar dúvidas sobre a ação benéfica das isoflavonas e inclusive investigam a possibilidade de algum risco em sua ingestão. Novos trabalhos deverão trazer informações mais conclusivas sobre os reais efeitos desses compostos presentes na soja.

Recebido para publicação em 22/04/2001.

Aceito para publicação em 1/11/2001.

\begin{abstract}
Evidences suggesting that soybean consumption is associated with health benefits has created considerable excitement within the dietetic and nutrition communities. However, the vast amount of research on this subject makes staying updated with the literature a daunting task. Therefore, the intent of this article is to briefly summarize current knowledge about the health effects of soyfoods. Arguably, most of the current interest in soy can be attributed to isoflavone content.
\end{abstract}

Key words: soybean; isoflavones; soy products

PUBLICATIO UEPG - Biological and Health Sciences, 7 (1): 39-46, 2001. 
Endereço para contato: ferrarir@uepg.br

\section{REFERÊNCIAS}

1 ADLERCREUTZ, H. et al. Dietary phyto-estrogen and the menopause in Japan. Lancet, v. 339, p.1233, 1992.

2 ANDERSON, J. J. B.; ANTHONY, M.; MESSINA, M.; GARNER, S. C. Effects of phyto-oestrogens on tissues. Nutr. Res. Rev., v. 12, n. 1, p. 75-116, 1999.

3 BARNES, S.; KIRK, M.; COWARD, L. Isoflavones and their conjugates in foods: extraction conditions and analysis by HPLC-mass spectrometry. J. Agr. Food Chem., v. 42, n.11, p. 2466-2474, 1994.

4 BRANDI, M. L. Natural and synthetic isoflavones in the prevention and treatment of chronic diseases. Calcified Tissue International, v. 61, p. S5-S8, 1997.

5 CAI, Q.; WEI, H. Effect of dietary genistein on antioxidant enzyme activities in SENCAR mice. Nutr. Cancer, v. 25, p.1-7, 1996.

6 ELDRIDGE, A. C.; KWOLEK, W. F. Soybean isoflavones: effect of environment and variety composition. J. Agr. Food. Chem., v. 31, n. 2, p. 394-396, 1983.

7 ENDO, H. Utilization of byproducts from food factories. Nippon Shoyu Kenkyusho Zasshi, v. 24, n. 4, p. 225-234, 1998.

8 EUGENBIO, Novo conceito de hormônio feminino. Disponível : http:// www.eugenbio.com. Data de acesso: 22 nov. 2001.

9 HESSLER, P. E.; LARSEN, P. E.; CONSTANTINOU, A. I.; SCHRAM, K. H.; WEBER, J. M. Isolation of isoflavones from soy-based fermentations of the erythromycin-producing bacterium Saccharopolyspora erythraea. Applied Microbiology and Biotechnology, v. 47, n. 4, p. 398-404, 1997.

10 HSU, J-T.; JEAN, M-A.; YING, C. Differential display screening for specific gene expression induced by dietary nonesteroidal estrogen. Molecular Reproduction and Development, v. 52, n. 2, p.141-148, 1999.

11 LUCAS, E. A.; KHALIL, D. A ; DAGGY, B. P.; ARJMANDI, B. H. Ethanol- 
46

extracted soy protein isolate does not modulate serum cholesterol in Golden Syriam hamsters: A model of postmenopausal hypercolesterolemia. Journal of Nutrition, v. 131, n. 2, p. 211-214, 2001.

12 MARTIN, P. M. ; HORWITZ, K. B.; RYAN, D. S.; MCGUIRE, W. L. Phytoestrogen interaction with estrogen receptors in human breast cancer cells. J. Endocrinol.., v. 103, p. 1860-1867, 1978.

13 MAZUR, W.; ALDERCREUTZ, H. Naturally occuring oestrogens in food. Pure and Applied Chemistry, v. 70, n. 9, p. 1759-1776, 1998.

14 MESSINA, M. J. Legumes and soybeans: an overview of their nutritional profiles and health effects. American Journal of Clinical Nutrition, v. 70, n. 3, (suppl. S), p.439S-450S, 1999.

15 NOTEBOOM, W. D.; GORSKI, J. Estrogenic effect of genistein and coumestrol diacetate. J. Endocrinol., v. 73, p. 736-743, 1963.

16 PLEWA, M. J.; WAGNER, E. D.; BERHOW, M. A.; CONWAY, A.; LANE RAYBURN, A.; ANDERSON, D. Antimutagenic activity of chemical fractions isolated from a commercial soybean processing by-product. Teratogenisis, Carcinogenesis and Mutagenisis, v. 19, n. 2, p. 121-135, 1999.

17 PROTEIN TECHNOLOGIES INTERNATIONAL. Waggle, D. H.; Bryan, B. A. Recovery of isoflavones from soy molasses. Int. C07H001-08. US 1998-86658, May 29, 1998; US 5919921, Jul. 6, 1999. US, 12p. Disponível : http://stneasy.cas.org/ tmp/56221-0212209355-200/694718976.html. Data de acesso: 18 Oct. 1999. 